University of Nebraska - Lincoln

DigitalCommons@University of Nebraska - Lincoln

Publications, Agencies and Staff of the U.S.

Department of Commerce

U.S. Department of Commerce

2011

Interplay of individual interactions and turbidity affects the functional response of three-spined sticklebacks Gasterosteus aculeatus

K. W. Vollset

University of Bergen, Knut.Vollset@uni.no

K. M, Bailey

NOAA

Follow this and additional works at: https://digitalcommons.unl.edu/usdeptcommercepub

Part of the Environmental Sciences Commons

Vollset, K. W. and Bailey, K. M, "Interplay of individual interactions and turbidity affects the functional response of three-spined sticklebacks Gasterosteus aculeatus" (2011). Publications, Agencies and Staff of the U.S. Department of Commerce. 324.

https://digitalcommons.unl.edu/usdeptcommercepub/324

This Article is brought to you for free and open access by the U.S. Department of Commerce at DigitalCommons@University of Nebraska - Lincoln. It has been accepted for inclusion in Publications, Agencies and Staff of the U.S. Department of Commerce by an authorized administrator of DigitalCommons@University of Nebraska - Lincoln. 


\title{
Interplay of individual interactions and turbidity affects the functional response of three-spined sticklebacks Gasterosteus aculeatus
}

\author{
K. W. Vollset*† AND K. M. BaILEY \\ *Department of Biology, University of Bergen, N-5020 Bergen, Norway and $\$$ Alaska \\ Fisheries Science Center, NOAA, National Marine Fisheries Service, 7600 Sand Point Way \\ NE, Seattle, WA 98115, U.S.A.
}

(Received 7 June 2010, Accepted 24 February 2011)

\begin{abstract}
The effects of turbidity, size and the presence of conspecifics on the functional response, feeding latency and activity in the three-spined stickleback Gasterosteus aculeatus were examined. A significant interaction between standard length and presence of conspecifics demonstrated an increase in attack rates of larger individuals in the presence of conspecifics. Attack rate was also higher in turbid water. Feeding latency decreased with prey concentration and presence of conspecifics, but was not affected by turbidity. Activity level did not change with prey levels, but increased with turbidity. These results can help to better understand how individual flexibility in the functional response can affect prey mortality according to environmental perturbation and social interaction at the level of the predator.

(c) 2011 The Authors

Journal of Fish Biology $\subset 2011$ The Fisheries Society of the British Isles
\end{abstract}

Key words: ecosystems; feeding interactions; fish behaviour; Holling-disc equation; predator-prey.

\section{INTRODUCTION}

The functional response of a predator's rate of consumption with increasing prey density is an important aspect of defining the relationship between predators and prey in ecosystems (Freitas et al., 2008). Many have questioned whether predation rate can be explained solely by prey density (Hassel et al., 1976; Werner, 1992), and a variety of models that include predator abundance and other biological and physical factors have surfaced in the wake of the Holling-disc equations (Holling, 1959). These models (as with the original Holling-disc equation), however, have been difficult to fit to a variety of systems (Skalski \& Gilliam, 2001).

The Holling-disc equation was developed to describe the functional response of individual predators, but work on schooling fishes has demonstrated that individual fishes may forage differently than schooling fishes (Major, 1978). This is generally attributed to the vigilance sharing hypothesis (Pitcher \& Magurran, 1983; Ranta \& Kaitala, 1991), which states that increasing surveillance capability in groups of

$\dagger$ Author to whom correspondence should be addressed at present address: Uni Miljø, LFI, Thormøhlensgt. 49 B, 5006 Bergen, Norway. Tel.: +55584723; email: Knut.Vollset@uni.no 
fishes will increase encounter rates with prey. In addition, vigilance sharing increases awareness of predator presence, leaving more time for mate finding and foraging. On the other hand, interference between individuals will counteract the positive attributes of foraging in groups, creating a fitness related trade-off between joining and leaving a group (Ranta et al., 1993). Earlier laboratory work has clearly demonstrated the efficiency of group foraging (Foster et al., 2001). These studies, however, did not evaluate the potential impact on functional responses and usually only examined two prey densities. Furthermore, the same individuals were not followed in the individual trials and group trials which makes it hard to evaluate whether the average response represents all individuals.

Behavioural and feeding interactions are also affected by the physical environment, e.g. light (Aksnes \& Giske, 1993), turbulence (Sundby et al., 1994) and temperature (Knutsen \& Salvanes, 1999). Quesenberry et al. (2007) showed that turbidity affects the reactive distance of three-spined stickleback Gasterosteus aculeatus L. 1758. Similar results have been demonstrated for the two-spotted goby Gobiusculus flavescens (Fabricius 1779) (Utne, 1997). In the case of G. aculeatus, however, no change in foraging efficiency (i.e. feeding lunges or number of prey consumed) was observed with changing turbidity, suggesting that the mortality inflicted on the prey population was not regulated by the visual limitation of the predator. As G. aculeatus are known to feed in groups of fish and group foraging is known to increase foraging efficiency, an interaction between turbidity and group foraging would be expected. For species that normally forage in groups and where there is an effect of facilitation and surveillance, the functional response will probably be dynamic with environmental perturbation (e.g. turbidity) and individual interactions.

This hypothesis is tested by measuring activity, latency to start feeding and the functional response of marked individual juvenile G. aculeatus in the presence of conspecifics and turbidity. Furthermore, as social hierarchy is important to individual foraging efficiency it is assumed that size is correlated with rank in a group and whether the functional response will be influenced by size when foraging together or with other individuals was tested.

\section{MATERIALS AND METHODS}

\section{COLLECTION AND HOLDING CONDITIONS}

Gasterosteus aculeatus are frequently used as a model predator in laboratory experiments. They are easy to handle in a laboratory environment, are social and adaptable and live in a broad range of environments, where they often constitute an important component of the local ecosystem. Juvenile G. aculeatus $(n=44)$ were collected from Big Ditch in the estuary system of the Skagit River, Washington, U.S.A. $\left(48^{\circ} 31^{\prime} \mathrm{N} ; 122^{\circ} 36^{\prime} \mathrm{W}\right)$. These fish regularly experience periods of turbidity when the incoming tide stirs up the silt in the estuary. Juvenile fish were collected at low tide with dip-nets (mean \pm s.D. standard length $\left.\left(L_{\mathrm{S}}\right)=28.9 \pm 0.4 \mathrm{~mm}\right)$. On arrival at the experimental facilities, the fish were kept in two 801 aquaria in a climate-controlled room and over a 2 day period they were acclimatized to a temperature of $15^{\circ} \mathrm{C}$ and salinity of 29.6 in a $16 \mathrm{~L}: 8 \mathrm{D}$ regime. During this time, the fish were fed ad libitum with a mixture of chopped shrimp and fish food pellets. Because of their small size and immaturity, no attempt was made to define sex. Eight fish were randomly chosen as experimental animals; their sizes were not significantly different from the remaining fish ( $t$-test, $P>0.05$ ) which were used in the conspecific treatments. To avoid an effect of unfamiliarity (Utne-Palm \& Hart, 2000), all three fish were allowed to familiarize for 2 weeks 
prior to the experiment. In this period the fish were introduced to newly hatched brine shrimp Artemia sp., by feeding them ad libitum. Beginning 2 days prior to the experiment, the fish were not fed to establish a high feeding motivation in all individuals.

\section{MARKING OF INDIVIDUALS}

Before marking, the eight individual G. aculeatus were sedated in a solution of tricaine methanesulphonate (MS-222). The tip of the third spine on the dorsal fin was then removed by placing the fish on a dry towel to hold the fish steady, and then snipping it off with surgical scissors. The fish was then allowed to recover in fresh sea water. No adverse affects on the behaviour or function of any of the individuals was observed after recovery throughout the trials.

\section{EXPERIMENTAL CHAMBERS}

Observations were conducted in eight separate 201 experimental chambers $(28 \mathrm{~cm} \times 28 \mathrm{~cm}$ $\times 40 \mathrm{~cm}$; Fig. 1) that were covered with black plastic on three sides and the bottom. In the front, a rectangular frame covered with black plastic with a small opening for observation was placed, so the fish could not see the observer. The experimental chambers had a small tube attached to the side which was used to introduce prey into the middle of the tank. The outside portion of the injection tube was attached to a syringe which allowed the observer to introduce the prey with a standardized volume $(30 \mathrm{ml})$ of water while observing the fish. This created a slowly diffusing patch of prey that would be dispersed in the water column within $c .1 \mathrm{~min}$. The direction of the tube into the tank was randomly assigned. Light was regulated in the replicated tanks by placing layers of black screening on top of the chamber. Light intensity measured at the surface varied from 2.8 to $3.1 \mu \mathrm{mol}$ photon $\mathrm{m}^{-2} \mathrm{~s}^{-1}$ between experimental chambers. This level was within the range experienced by G. aculeatus feeding in nature, and particularly in turbid water. Water was still and non-aerated throughout each experimental replicate and was exchanged 1 day prior to conducting each replicate. Temperature varied from 14.9 to $15 \cdot 0^{\circ} \mathrm{C}$ and salinity 29.6 to 29.8 throughout the experiment.

\section{EXPERIMENTAL DESIGN}

To test the effect of presence of conspecifics $\left(C_{\mathrm{P}}\right)$ and turbidity $(\mathrm{T})$ on the functional response of G. aculeatus, a repeated crossed factorial design was applied, where eight marked

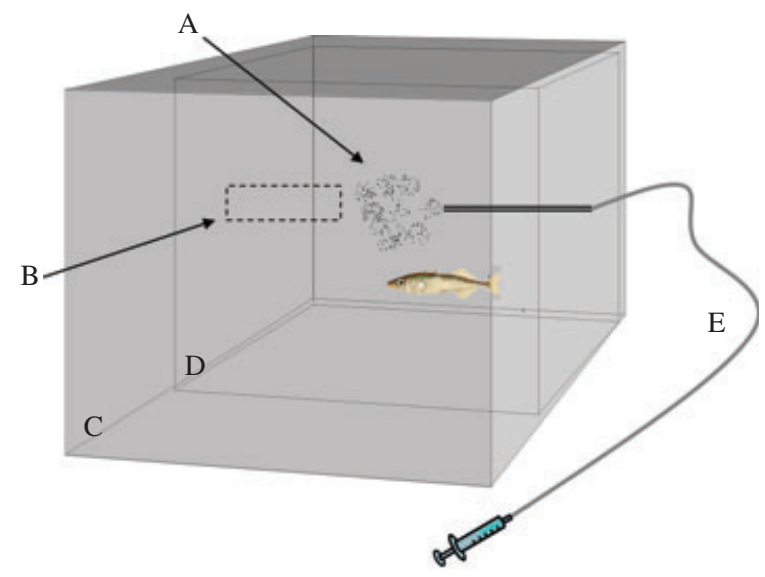

FIG. 1. Illustration of observational chamber. A, Artemia sp.; B, observation opening; C, black lining tent; D, observational chamber/aquarium $(28 \mathrm{~cm} \times 28 \mathrm{~cm} \times 40 \mathrm{~cm})$; E, hose with syringe to insert prey. 
individuals were observed over a range of prey densities (3, 6, 11, 30 and 200 Artemia sp. $\left.1^{-1}\right)$, either alone or in the presence of six conspecifics (taken from the remaining 36 fish) both with and without turbidity. The prey densities were observed in a random order to avoid the effect of habituation. The fish were introduced to the observational chamber to acclimate at least $3 \mathrm{~h}$ before each trial. Observation started immediately after food was introduced. After each trial, the individual marked fish were placed in marked individual containers where they were fed enough to keep the fish from starving while maintaining a high level of feeding motivation. The six conspecific fish were placed back into another container and given the same treatment. Treatments and replicates were randomly assigned to day. In turbidity trials, all design elements were the same except for introduction of turbidity. Turbidity was produced by adding a fine bentonite clay suspension to the experimental chambers as suggested in Quesenberry et al. (2007). To create equal turbidity in all replicates, equal amounts were added from a stock clay suspension that was vigorously aerated. The experimental chambers were aerated just prior to the experiment so that the clay would remain suspended throughout the trial. The turbidity level was chosen on the basis of preliminary trials to establish a level where visual behavioural observations could still be accomplished. Water samples were taken after each trial and absorbance was measured using a spectrophotometer (Shimadzu UV120-02; www.ssi.shimadzu.com), to estimate mean turbidity level and variance between replicates [mean \pm S.D. $6 \cdot 8 \pm 2 \cdot 2$ beam attenuation coefficient $\left(\mathrm{m}^{-1}\right)$ ]. At the end of the experiments, the marked fish were anaesthetized with MS-222 and measured for $L_{\mathrm{S}}$ and mass.

\section{EXPERIMENTAL PROTOCOL}

Each attack was recorded by visually observing the marked individual for a period of 5 min from immediately after introduction of food and recording all observations on a dictaphone. Attack was assumed from posture and movement and was easily identified. Feeding success was difficult to quantify due to the size of the prey and speed of attack in high prey concentrations and was thus not attempted. In addition, the number of swimming movements (defined as a continuous position displacement longer than two body lengths), turns (all movements not defined as swimming or attack behaviours) and area changes (defined as movement from one-quarter of the tank to another area) were observed. The recordings were later analysed by listening to each recorded track and logging each type of observation (attack, movement, turn and area change). The attack rate was defined as number of attacks s ${ }^{-1}$ during the period of observation, as explained in Sørnes \& Aksnes (2004). As the prey were depleted during the $5 \mathrm{~min}$ trial in the lower concentration treatments, attack rate was only calculated until about half of the prey were consumed. Furthermore, replicates that reached half depletion before 1 min were excluded because the Artemia sp. would not have had sufficient time to disperse in the body of water. To estimate time to half depletion in the treatments with conspecifics, the attack rate was calculated first for the single treatments and then used to calculate how long it would take six individuals to consume half of the prey at the same rate. In these estimates it was assumed that each attack led to ingestion of Artemia sp., which may somewhat overestimate ingestion rates because G. aculeatus are known to both miss and reject the prey they have attacked (Quesenberry et al., 2007). To test sensitivity to this assumption, different probabilities of capture successes were included to estimate time to half depletion, but large changes in the functional response variable were not observed in these simulations under reasonable conditions. Feeding latency $\left(F_{\mathrm{L}}\right)$ was defined as the time between the introduction of prey and when the marked fish attacked its first prey.

\section{DATA ANALYSIS}

All analysis was done in R 2.8.1. (www.r-project.org). The data were analyzed by applying the Holling-disc equation (Holling, 1959): $f=a N(1+a h N)^{-1}$, where $f$ is the feeding rate (number of prey attacked $\mathrm{s}^{-1}$ ), $N$ is the prey density (prey $\mathrm{m}^{-3}$ ), $h$ is the handling time (pursuit, capture and consumption of one prey item in s) and $a$ is the attack rate 


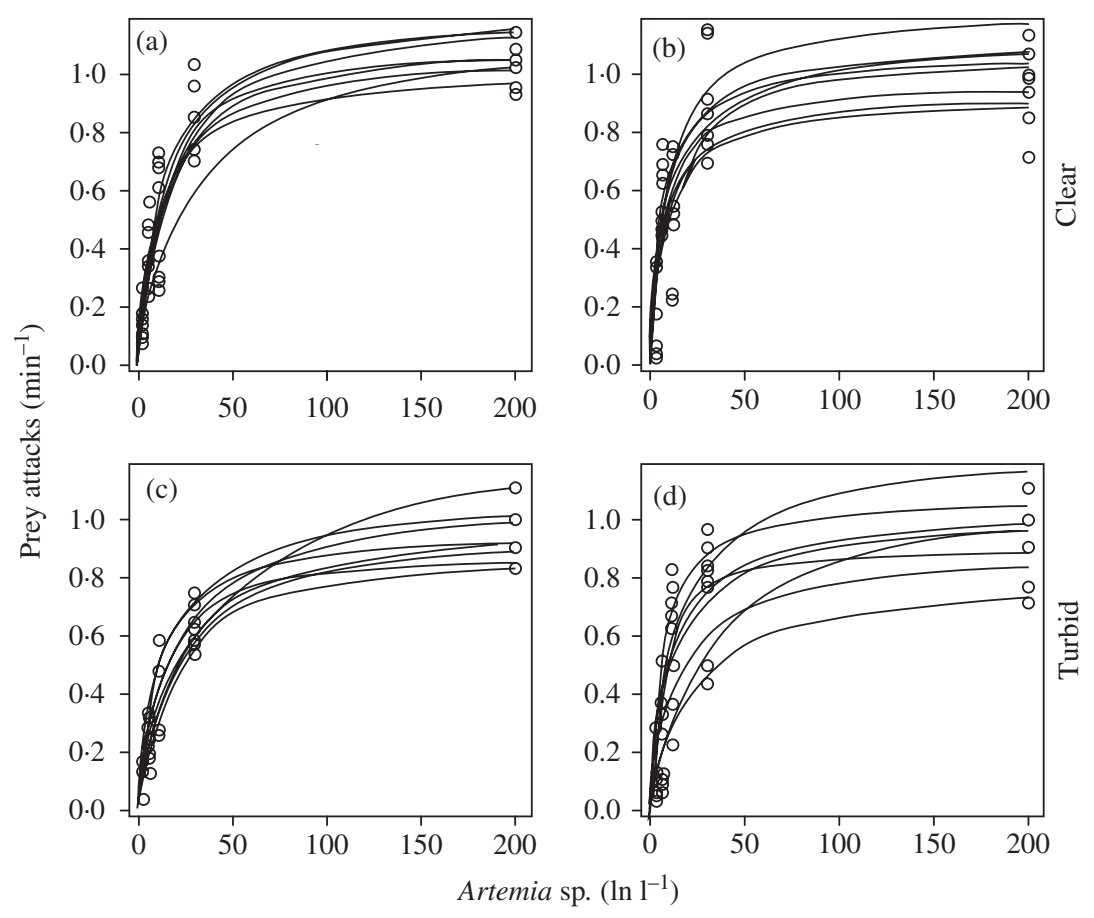

FIG. 2. Original data $(\mathrm{O})$ and individual non-linear fits (_ aculeatus were feeding (a), (c) together with six conspecifics and (b), (d) alone in (a), (b) clear and (c), (d) turbid water.

$\left(\mathrm{m}^{-3} \mathrm{~s}^{-1}\right)$. Estimates of the parameters $a$ and $h$ for each marked individual in each treatment was done by non-linear regression using 'stats' library in R (Fig. 2). The attack rate, $a$ [as in Holling (1959)], is defined in the literature as the 'encounter rate kernel' or clearance rate (Sørnes \& Aksnes, 2004). It is here defined as attack rate because only the number of attacks was measured and no attempts were made to estimate attack success. Thus, the use of the term clearance rate would be misleading. To be able to establish the asymptotic level of feeding, a high feeding concentration was applied (200 Artemia sp. $\left.1^{-1}\right)$. This level was based on preliminary trials and literature (Karagosian, 2000). It was assumed that feeding will not decrease at higher prey concentrations due to predator confusion effects.

A linear mixed model with the individual as a random effect was applied to test the effect of turbidity $(T)$ and conspecifics $\left(C_{\mathrm{P}}\right)$ on attack rate, $a$. The $L_{\mathrm{S}}$ of fish was set as a covariate. The model was fitted through stepwise removal of non-significant terms according to an AIC criterion and non-significant $P$-values, starting with a saturated model. The handling time, $h$, demonstrated little variation between the individuals (mean \pm s.D. $0.95 \pm 0.11 \mathrm{~s}$ ) and was set at a constant; this did not have any effect on the final results of the model of attack rate.

The $F_{\mathrm{L}}$ was analysed using a linear mixed model with individual as a random effect, $T$ and $C_{\mathrm{P}}$ as predictor variables and $\ln$ of concentration as a covariate. As $F_{\mathrm{L}}$ was skewed towards zero, the data were analysed on a ln transformed scale. For activity level, defined as all behavioural observations (turn, swim and attack) divided by s, and area change, the $C_{\mathrm{P}}$ was excluded as a predictor variable because observations were done throughout the trial, and thus could not be corrected for decreased prey concentration in $C_{\mathrm{P}}$ trials. Model fitting was done as explained above. Model assumptions of homoscedasticity and normal distribution of residuals were assessed using diagnostic plots. 


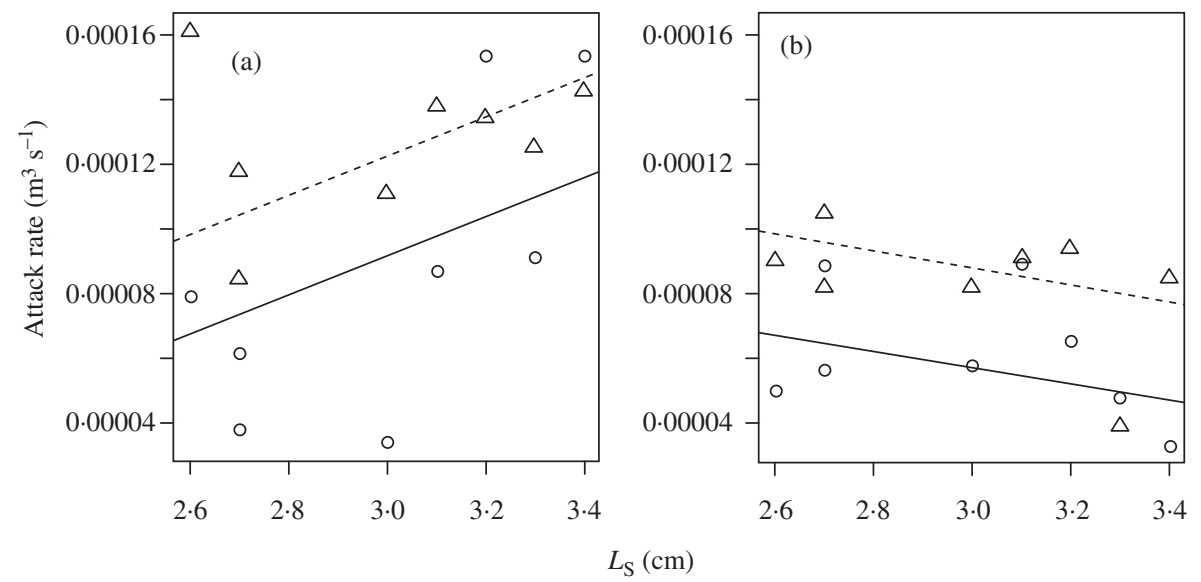

FIG. 3. Plot of 'encounter rate kernel' (here defined as attack rate) and standard length $\left(L_{\mathrm{S}}\right)$ in (a) treatment when feeding with six other individuals and (b) feeding alone, in both clear (-O-) and turbid $\left(--_{-}^{-}\right)$ water, with fitted lines from the fixed parameter of the linear mixed model.

\section{RESULTS}

Attack rate, $a$, was significantly affected by, turbidity $(T), L_{\mathrm{S}}$ of the marked fish and the presence of $C_{\mathrm{P}}$. Both $T$ [Linear mixed effects (LME), $F_{1,21}=13 \cdot 5$, $P<0.01]$ and $C_{\mathrm{P}}\left(\mathrm{LME}, F_{1,40}=21.08, P<0.01\right)$ had a positive effect on attack rate [Fig. 3(a)]. In addition, a significant interaction term between $L_{\mathrm{S}}$ and $C_{\mathrm{P}}$ demonstrated a positive slope between attack rate and $L_{\mathrm{S}}$ when conspecifics were present and a slightly negative slope when alone [LME, $F_{1,21}=8 \cdot 33, P<0 \cdot 05$; Fig. 3(b)]. Individual variation and residual deviance in $a$ were estimated at $1.25 \times 10^{-05}$ and $2 \cdot 38 \times 10^{-05}$, respectively.

$F_{\mathrm{L}}$ decreased with increased prey concentration (LME, $F_{1,140}=18.46, P<0.001$ ) and presence of conspecifics (LME, $F_{1,140}=29.48, P<0.001$; Fig. 4). There was

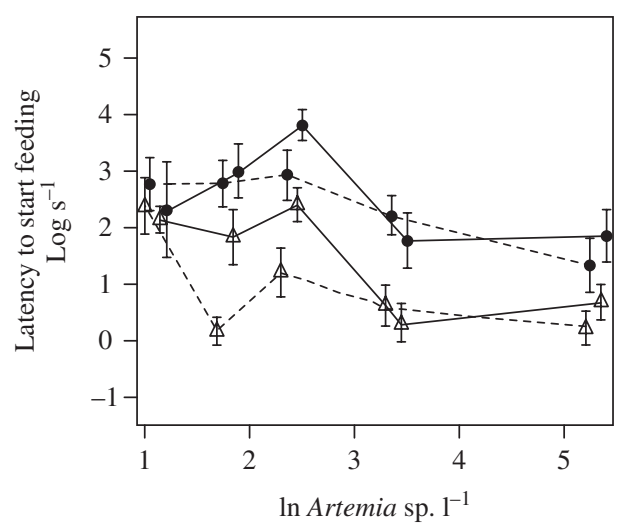

FIG. 4. Time until first attack (feeding latency, $F_{\mathrm{L}}$ ) plotted against concentration of Artemia sp. $1^{-1}$ for clear $\left({ }_{(}\right)$and turbid (_._. $)$water, when feeding alone $(\bullet)$ and together with six other individuals $(\triangle)$. 
an indication of increased $F_{\mathrm{L}}$ with turbidity, but this was not significant. Individual variation and residual deviance in $F_{\mathrm{L}}$ were estimated at 1.32 and $4.59 \mathrm{~s}$, respectively.

Activity level did not change with prey concentration, but increased with turbidity (LME, $F_{1,66}=7 \cdot 25, P<0.01$ ). Individual variation and residual deviance in activity level were estimated at 0.18 and 0.46 movements $\mathrm{s}^{-1}$. Area change was not affected by any of the treatments.

\section{DISCUSSION}

This study has demonstrated that the functional response of individual G. aculeatus increases in the presence of conspecifics and that the degree of change is dependent on size. Larger fish were more likely to increase their attack rate in the presence of conspecifics than small fish. Turbidity had a simple additive effect on attack rate, with increasing attack rates in turbid water. The observed changes in attack rate can be viewed as combined effects of adaptive and mechanistic responses of individuals to social interference and facilitation in varying turbidity environments.

The presence of conspecifics increased the average attack rate of G. aculeatus. This is in line with other work that has demonstrated increased attack rates in schools of fishes (Peuhkuri, 1998). Whether this is an adaptive and flexible response (Magurran, 1993) of the individual to the presence of conspecifics due to increased competition, or a function of increased surveillance, is difficult to 'tease apart'. Aggression was observed in some of the replicates with low prey density, and smaller individuals were clearly targeted by the larger individuals (however, this was not statistically proven here as such incidents were not quantified in this study). Larger individuals increased their attack rate when other individuals were present, which could be a display of dominance when in a group. There are both negative and positive sides to foraging in a group, and the choice of participating in a group depends on the cumulative fitness determined by both predator and prey encounters (Clark \& Mangel, 1984; Ranta et al., 1993). Fitness changes caused by foraging can be linked to both the period before encounter of a patch of prey (facilitation) and afterwards (e.g. interference and competition). This work has mainly focused on the potential adaptive values of foraging in a group after a patch of prey has been encountered and suggests that, dependent on size, juvenile G. aculeatus will change attack rate to adapt to the increased competition of conspecifics.

Turbidity had a simple and positive additive effect on attack rate and activity of G. aculeatus, and the level applied in this experiment was probably not inhibiting to foraging activity. Turbidity is generally thought to affect the reactive distance in visual foragers (Aksnes \& Utne, 1997; Quesenberry et al., 2007), and a lot of emphasis has been put on the direct negative effects of decreased water clarity in coastal and estuarine aquatic systems due to anthropogenic influences (Aksnes, 2007). Several experiments, however, have shown that both reactive distance and foraging rate increase at intermediate turbidity levels (Utne-Palm, 1999; Meager et al., 2005; Meager \& Batty, 2007; Quesenberry et al., 2007; Webster et al., 2007). This is usually attributed to two non-mutually exclusive hypotheses: the motivation hypothesis, which suggests that activity should increase due to lowered conspicuousness to predators, and the physical effect hypothesis, which suggests that turbidity enhances the contrast between the prey and its surroundings, thus increasing reactive 
distance (Utne-Palm, 1999). A third possible mechanistic explanation is that activity increases due to decreased visibility in order to more actively survey the environment. The turbidity level applied in this experiment was comparable to intermediate levels of turbidity of earlier work (6.8 beam attenuation $\mathrm{m}^{-1}$; Utne-Palm, 1999; Meager et al., 2005; Meager \& Batty, 2007), and the results are in line with earlier observed increases in attack rate. It is not possible to separate the three hypotheses, but parallel observation of increased activity in turbid water might give some support to a motivation or surveillance hypothesis. At the same time, however, the fact that the turbidity effect was purely additive lends some support to the physical effect hypothesis. Nilsson et al. (2008) also argued that interference effects might increase in turbid water for pike Esox lucius L. 1758, based on observations that solitary foraging increased with turbidity, but not when other individuals were present. Neither decreased [due to decreased visual cues between individuals] nor increased [as suggested by Nilsson et al. (2008)] interference was observed during the experiments (i.e. no interaction between turbidity and presence of conspecifics). High levels of turbidity, however, were not applied.

The $F_{\mathrm{L}}$ decreased with prey concentration, and this is probably due to either increased conspicuousness or encounter rate at the higher prey densities. In addition, $F_{\mathrm{L}}$ decreased in the presence of conspecifics, possibly because fish were more aware of the prey when other individuals started feeding. This phenomenon, often described as the information sharing (IS) hypothesis (Clark \& Mangel, 1984), has been observed over a range of species in ecology (Ranta et al., 1993) and is one of the most important reasons for foraging in groups. Turbidity level, however, did not change $F_{\mathrm{L}}$, and consequently the increased effect due to presence of conspecifics did not differ in turbid and clear water. The turbidity level was probably not sufficiently high to deter visual range within the confinement of the experimental chamber. In nature, however, vision is probably an important long-range observational cue, and given that turbidity directly affects the beam attenuation of light, it should be expected that small turbidity changes have a large effect on behaviour expressed over larger scales, e.g. sexual selection (Heuschele et al., 2009).

The Holling-disc equation was developed by Holling (1959) as a mechanistic explanation for the functional response based on handling time and the 'encounter rate kernel', $a$. The original work was based on observations of single individuals measured feeding at varying 'prey' densities and is one of the (several) assumptions of the model. Even so, the disc equations have often been applied to experiments with groups of individuals (Townsend \& Risebrow, 1982; Colton, 1987; Buckel \& Stoner, 2000), and in field work, data are inevitably aggregated. There have been several attempts to include predator interference in models, but no single model that includes a parameter for such interference has been successful in fitting to the variety of ecosystems (Skalski \& Gilliam, 2001). Results from this study suggest that attack rate is dynamic, not only with environmental perturbation (i.e. turbidity) but also with interference (as suggested by former models) and social hierarchy (as suggested by the size interaction). To fully understand the effect of predator interference on the average functional response of a group of fishes, it is important to focus on individual variability and its potential interaction with the physical and biological environment.

Trophic interactions in ecosystems are complex, and much effort has been made to understand how physical (e.g. turbidity) and biological (e.g. behaviour) factors 
interact to create dynamic population processes (Cuker, 1993). As data are generally expressed in fluctuating biomass or numbers of individuals at different trophic levels, it is not always intuitive how the functional response of an individual scales up to the average functional response of a group or population of individuals (Holling, 1987). Here, it is demonstrated how a simple behavioural response between individuals can alter the average population functional response and individual functional response differently. Furthermore, aggregative responses and higher species order interactions (Werner, 1992) must also be taken into consideration when trying to understand how functional response scales up to populations and assemblages, and varies with environmental perturbations.

Some discussion on assumptions and potential sources of error is warranted. The experimental setup did to some degree violate the assumption of constant prey concentration. Attempts were made to correct for this by only measuring the attack rate before depletion affected the functional response. In most cases, the experiments were relatively short, lasting from 1 to $4 \mathrm{~min}$. Furthermore, prey were not homogeneously distributed as they were introduced into the experimental tank after the predators. This was due to the fact that all predators needed to be acclimated to the experimental tanks before starting the experiment, so that they would start feeding at the same time. Although the method of observation did not make it possible to distinguish successful attacks, comparison of 'encounter rate kernel' or attack rate with other published literature (Sørnes \& Aksnes, 2004) demonstrates that these results are similar to other experiments. Furthermore, the aim of this study was not to establish the absolute values of handling time and 'encounter rate kernel', but rather qualitatively compare treatments.

This work has demonstrated that the functional response is affected both by presence of conspecifics and turbidity. The effect of conspecifics also depends on size of the individual, pointing to social hierarchy and dominance as an important aspect of foraging behaviour. These results could have important implications for understanding how functional response scales up to groups and populations of individuals.

Reference to trade name does not imply endorsement by the National Marine Fisheries Service, NOAA. We are indebted to S. Porter for help with collecting sticklebacks, setting up the laboratory and commenting on the manuscript. We greatly appreciate the constructive critiques and discussions with A. C. Utne-Palm, A. F. Opdal and A. Folkvord.

\section{References}

Aksnes, D. L. (2007). Evidence for visual constraints in large marine fish stocks. Limonology and Oceanography 52, 198-203.

Aksnes, D. L. \& Giske, J. (1993). A theoretical model of aquatic visual feeding. Ecological Modelling 67, 233-250.

Aksnes, D. L. \& Utne, A. C. W. (1997). A revised model of visual range in fish. Sarsia 82, $137-147$

Buckel, J. A. \& Stoner, A. W. (2000). Functional response and switching behavior of youngof-the-year piscivorous bluefish. Journal of Experimental Marine Biology and Ecology 245, 25-41.

Clark, W. C. \& Mangel, M. (1984). Foraging and flocking strategies: information in an uncertain environment. The American Naturalist 123, 626-641.

Colton, T. F. (1987). Functional response models to include a second prey type: an experimental test. Ecology 68, 900-912. 
Cuker, B. E. (1993). Suspended clay alter the trophic interactions in the plankton. Ecology 74, 944-953.

Foster, G. F., Ritz, D. A., Osborn, J. E. \& Swasling, K. M. (2001). Schooling affects the feeding success of Australian salmon (Arripis trutta) when preying on mysid swarms (Paramesopodopsis rufa). Journal of Experimental Marine Biology and Ecology 161, 93-106.

Freitas, V., Bailey, K. \& Van der Veer, H. W. (2008). Population regulation of epibenthic species in coastal ecosystems, with implications for latitudinal patterns. Journal of Sea Research 60, 105-116.

Hassel, M. P., Lawton, J. H. \& Beddington, J. R. (1976). The components of arthropod predation I. The prey death-rate. Journal of Animal Ecology 45, 135-164.

Heuschele, J., Mannerla, M., Gienapp, P. \& Candolin, U. (2009). Environment-dependent use of mate choice cues in sticklebacks. Behavioral Ecology 20, 1223-1227.

Holling, C. S. (1959). Some characteristics of simple types of predation and parasitism. The Canadian Entomologist 91, 385-398.

Holling, C. S. (1987). Simplifying the complex - the paradigms of ecological function and structure. European Journal of Operational Research 30, 139-146.

Karagosian, M. (2000). The influence of prey density and environmental complexity on the foraging behavior of the threespine stickleback Gasterosteus aculeatus. PhD Dissertation, State University of New York, College of Environmental Science and Forestry, Syracuse, NY, USA.

Knutsen, I. \& Salvanes, A. G. V. (1999). Temperature-dependent digestion handling time in juvenile cod and possible consequences for prey choice. Marine Ecology Progress Series 181, 61-79.

Magurran, A. E. (1993). Individual differences and alternative behaviours. In Behaviour of Teleost Fishes, 2nd edn (Pitcher, T. J., ed.), pp. 441-468. London: Chapman \& Hall.

Major, P. F. (1978). Predator-prey interactions in two schooling fishes, Caranx ignobilis and Stolephorus purpureus. Animal Behavior 26, 760-777.

Meager, J. J. \& Batty, R. S. (2007). Effects of turbidity on the spontaneous and prey-searching activity of juvenile Atlantic cod (Gadus morhua). Philosophical Transactions of the Royal Society 362, 2123-2130.

Meager, J. J., Solbakken T., Utne-Palm, A. C. \& Oen, T. (2005). Effects of turbidity on the reactive distance, search time, and foraging success of juvenile Atlantic cod (Gadus morhua). Canadian Journal of Fisheries and Aquatic Sciences 62, 1978-1984.

Nilsson, P. A., Jacobsen, L., Berg, S. \& Skov, C. (2008). Environmental conditions and intraspecific interference: unexpected effects of turbidity on pike (Esox lucius) foraging. Ethology 115, 33-38.

Peuhkuri, N. (1998). Shoal composition, body size and foraging in sticklebacks. Behavioral Ecology and Sociobiology 43, 333-337.

Pitcher, T. J. \& Magurran, A. E. (1983). Shoal size, patch profitability and information exchange in foraging goldfish. Animal Behaviour 31, 546-555.

Quesenberry, N. J., Allen, P. J. \& Chec, J. J. (2007). The influence of turbidity on threespined stickleback foraging. Journal of Fish Biology 70, 965-972.

Ranta, E. \& Kaitala, V. (1991). School size affects individual feeding success in three-spined sticklebacks (Gastorosteus acuelatus L.). Journal of Fish Biology 39, 733-737.

Ranta, E., Rita, H. \& Lindström, K. (1993). Competition versus cooperation: success of individuals foraging alone and in groups. The American Naturalist 142, 45-58.

Skalski, G. T. \& Gilliam, J. F. (2001). Functional response with predator interference: viable alternatives to the Holling type II model. Ecology 82, 3038-3092.

Sørnes, T. A. \& Aksnes, D. (2004). Efficiency in visual and tactile zooplanktivores. Limnology and Oceanography 49, 69-75.

Sundby, S., Ellertsen, B. \& Fossum, P. (1994). Encounter rates between $1^{\text {st }}$-feeding cod larvae and their prey during moderate to strong mixing. ICES Marine Science Symposia 198, $393-405$.

Townsend, C. R. \& Risebrow, A. J. (1982). The influence of light level on the functionalresponse of a zooplanktonivorous fish. Oecologia 53, 293-295. 
Utne, A. C. W. (1997). The effect of turbidity and illumination on the reaction distance and search time of the marine planktivore Gobiusculus flavescens. Journal of Fish Biology 50, 926-938.

Utne-Palm, A. C. (1999). The effect of prey mobility, prey contrast, turbidity and spectral composition on the reaction distance of Gobiusculus flavescens to its planktonic prey. Journal of Fish Biology 54, 1244-1258.

Utne-Palm, A. C. \& Hart, P. J. B. (2000). The effects of familiarity on competitive interactions between threespine sticklebacks. Oikos 91, 225-232.

Webster, M. M., Atton, N., Ward, A. J. W. \& Hart, P. J. B. (2007). Turbidity and foraging rate in threespine sticklebacks: the importance of visual and chemical prey cues. Behavior 144, 1347-1360.

Werner, E. E. (1992). Individual behavior and higher-order species interactions. The American Naturalist 140, 5-32. 